Article

\title{
Development of Lateral Flow Immunochromatographic Assays Using Colloidal Au Sphere and Nanorods as Signal Marker for the Determination of Zearalenone in Cereals
}

\author{
Mingfei Pan ${ }^{1,2}$, Tianyu Ma ${ }^{1,2}$, Jingying Yang ${ }^{1,2}$, Shijie $\mathrm{Li}^{1,2}$, Shengmiao Liu ${ }^{1,2}$ and \\ Shuo Wang ${ }^{1,2, *}$ \\ 1 State Key Laboratory of Food Nutrition and Safety, Tianjin University of Science \& Technology, \\ Tianjin 300457, China; panmf2012@tust.edu.cn (M.P.); maty1128@126.com (T.M.); yangjy0823@126.com (J.Y.); \\ 1sj930427@126.com (S.L.); 1sm20000711@outlook.com (S.L.) \\ 2 Key Laboratory of Food Nutrition and Safety, Ministry of Education of China, Tianjin University of Science \\ and Technology, Tianjin 300457, China \\ * Correspondence: s.wang@tust.edu.cn; Tel.: +86-022-6091-2493
}

Received: 14 February 2020; Accepted: 26 February 2020; Published: 4 March 2020

check for updates

\begin{abstract}
This paper describes the development of lateral flow immunochromatographic assays (ICAs) using colloidal Au sphere (SP) and nanorods (NRs) as signal markers for the determination of zearalenone (ZEN) in cereals. The developed ICAs can detect the analyte ZEN within a short time (10 min), and achieve lower limit of detection (LOD). This is the first time that the AuNRs are used as signal probe in immune test strip for ZEN detection. For colloidal AuSP immunochromatographic analysis (AuSP-ICA), the LODs in solution and spiked cereal sample were $5.0 \mu \mathrm{g} \mathrm{L} \mathrm{L}^{-1}$ and $60 \mu \mathrm{g} \mathrm{kg}{ }^{-1}$, and for AuNRs immunochromatographic analysis (AuNRs-ICA) the two LODs achieved $3.0 \mu \mathrm{g} \mathrm{L}^{-1}$ and $40 \mu \mathrm{g} \mathrm{kg}^{-1}$, respectively. These two proposed ICAs have minor cross-reaction to the structural analogs of $\mathrm{ZEN}$, and no cross-reactivity with aflatoxin $\mathrm{B}_{1}, \mathrm{~T}-2$ toxin, ochratoxin $\mathrm{A}$, deoxynivalenol, fumonisin $B_{1}$. Both of the developed ICAs can specifically and sensitively detect ZEN in cereals, providing an effective strategy for rapid screening and detection of ZEN in a large number of food samples.
\end{abstract}

Keywords: zearalenone; immunochromatographic assay; colloidal Au sphere; Au nanorods; cereals

\section{Introduction}

Zearalenone (ZEN), also known as F-2 toxin, is a secondary metabolite produced by Fusarium, which mainly contaminates corn, wheat, and other cereals [1,2]. ZEN has a similar structure with the endogenous estrogen and can competitively bind to the estrogen receptor, which makes the hormone of animal body maladjusted and finally destroys the reproductive system [3,4]. The contamination range of ZEN in grain is very wide. It cannot only enter the human body through direct or indirect intake, but can be transmitted to the fetus through placenta. ZEN with high exposure and high accumulation concentration can inhibit the activity of enzyme and stimulate the growth of breast cancer cells. Modern research has confirmed that ZEN has typical immunotoxicity, genotoxicity, and reproductive toxicity, which seriously threatens people's health [5-7]. As a result, many countries and organizations have stipulated the maximum residue limits (MRLs) for ZEN in cereals (the United States: $20-100 \mu \mathrm{g} \mathrm{kg}$ for cereals [8]; European Union: $350 \mu \mathrm{g} \mathrm{kg}^{-1}$ in raw maize products [9]; China: $60 \mu \mathrm{g} \mathrm{kg}^{-1}$ in cereals and cereals products [10]). Therefore, the development of effective methods for ZEN detection in various foods is of great significance for protecting the health of people. 
At present, the analysis strategy for ZEN in foods is mainly the accurate and precise analysis using analytical instruments based on chromatographic separation and mass spectrometry, including high-performance liquid chromatography, gas chromatography, and related analytical methods combined with mass spectrometry [11-13]. This type of methods is widely recognized by testing agencies because of its high accuracy, good sensitivity, and very high reproducibility. On the other hand, because of the limit of large analytical instruments, these methods require a relatively cumbersome pre-treatment process to deal with complex food matrices, resulting in having a certain distance in terms of detection throughput and convenience. As known, the immunoassays based on the specific binding of antigen-Ab have obvious advantages in the rapid screening and analysis of a large number of samples. Established relatively mature immunoassays to ZEN included enzyme-linked immunosorbent assay (ELISA) $[14,15]$ and colloidal gold [16-18] and fluorescent $[19,20]$ immunochromatographic test strips. The ELISA with high sensitivity and specificity does not require the high purity of tested samples, but needs skillful operators. The lateral flow immunochromatographic assays strips (ICAs) are easy to operate, convenient to carry, and can directly visualize qualitative or semi-quantitative analysis of the target, having remarkable application prospects for the detection of toxic and harmful substances in foods [21,22]. Based on different markers such as colloidal Au spheres (SP) [23-25], fluorescent microspheres [26,27], quantum dot [28,29], etc., ICAs products (test strips) are easy to use and inexpensive, making them have very important applications in fast, on-site screening of large numbers of food samples. Au nanorods (AuNRs) is one of the more precious metal nanomaterials studied in recent years. The different aspect ratios of AuNRs enable them to show different absorption spectra or different colors, which is very suitable for rapid screening of visualization. There are some reports about the application of AuNRs in toxin and mycotoxins in food products [30-32]. The AuNRs was applied as a signal output in ELISA or biosensor, achieving qualitative and quantitative detection for the targets. So far, the research on AuNRs has mostly focused on analysis strategies based on fluorescent signals [33] and biological imaging [34], but less research on the visible analysis [35].

In this study, two Au nanomaterials-colloidal Au SP and NRs were successfully prepared and used to develop two immunochromatographic test strips for the visual detection of ZEN in cereals. Based on the physical and chemical properties of colloidal Au SP and NRs, colloidal AuSP immunochromatographic analysis (AuSP-ICA) and AuNRs immunochromatographic analysis (AuNRsICA) provide an effective analysis strategy for monitoring and analysis of this toxin in food products. Additionally, this is the first time to detect ZEN in food products using AuNRs as the signal marker.

\section{Materials and Methods}

\subsection{Materials}

The anti-ZEN monoclonal antibody (anti-ZEN-Ab, $1 \mathrm{mg} \mathrm{mL}^{-1}$ ) and coating antigen, the conjugate of ZEN-ovalbumin (ZEN-OVA, $2.94 \mathrm{mg} \mathrm{mL}^{-1}$ ), were purchased from Shandong Lvdu Biotechnology Co. Ltd. (Shandong, China). The chloroauric acid $\left(\mathrm{HAuCl}_{4}\right)$ and trisodium citrate for the synthesis of $\mathrm{Au}$ SP and NRs were obtained from Sigma-Aldrich (St. Louis, MO, USA). The goat anti-mouse Ab $\left(4 \mathrm{mg} \mathrm{mL}^{-1}\right)$, aflatoxin $\mathrm{B}_{1}\left(\mathrm{AFB}_{1}\right), \mathrm{ZEN}$, and the analogues ( $\alpha$-zearalenol, $\alpha$-zearalanol, $\beta$-zearalenol, zearalanone, $\beta$-zearalanol) $\left(1.0 \mathrm{mg} \mathrm{L}^{-1}\right)$ were also purchased from Sigma-Aldrich (St. Louis, $\mathrm{MO}$, USA). Other mycotoxins T-2, ochratoxin A (OTA), deoxynivalenol (DON), and fumonisin $\mathrm{B}_{1}\left(\mathrm{FB}_{1}\right)$ were purchased from Toronto Research Chemicals (Toronto, Canada). Tris, sucrose, polyvinylpyrrolidone (PVP), poloxamer 18 solution (F68), TritonX-100, SDS-L, and polyethylene glycol ( $\left.\mathrm{PEG}_{200}\right)$ for the preparation of gold-label working buffer were purchased from Sangon Biotech Co., Ltd. (Shanghai, China). Hexadecyl trimethyl ammonium bromide (CTAB, 99\%) was purchased from Solarbio (Beijing, China). Silver nitrate $\left(\mathrm{AgNO}_{3}\right)$ and ascorbic acid for NRs synthesis were obtained from the Sinopharm Chemical Reagent Co., Ltd. (Shanghai, China).

Nitrocellulose (NC) membranes (HF90, HF135, and HF180 with capillary flow rates of $90 \mathrm{~s} / 4 \mathrm{~cm}$, $135 \mathrm{~s} / 4 \mathrm{~cm}$ and $180 \mathrm{~s} / 4 \mathrm{~cm}$, respectively) were purchased from Millipore Corporation (Bedford, MA, 
USA). Sample pad, conjugate pad and absorbent pad, and polyvinyl chloride (PVC) sheets were purchased from Kinbio Tech Co. (Shanghai, China). Single-channel pipettes (2.5-1000 $\mu \mathrm{L})$ were obtained from Thermo Corporation (USA). A vortex machine (HQ-60) was purchased from North Tongzheng Biotechnology Development Company (Beijing, China). Milli-Q Ultrapure Water System was purchased from Milli-Q Millipore, (Bedford, MA, USA). The UV-visible spectrophotometer (Cary 50 Bio) was obtained from Varian (California, USA). Three-dimensional film-gold spraying instrument (HM3030) and the microcomputer automatic cutting machine (ZQ2002) were purchased from Shanghai Jinbiao Biotechnology Co., Ltd. (Shanghai, China) for the preparation of test strips.

\subsection{Preparation of Colloidal Au SP and NRs}

Colloidal AuSP was synthesized according to the previously reported synthesis method with some new modifications [25]. Total of $99.0 \mathrm{~mL}$ of water and $1.0 \mathrm{~mL}$ of $\mathrm{HAuCl}_{4}(1 \%)$ were added into a glassy bottle, and the mixture was stirred and heated at $100{ }^{\circ} \mathrm{C}$. When the mixture begins to boil, $2.5 \mathrm{~mL}$ of trisodium citrate $(1 \%)$ was added immediately. When the mixture boils violently, the heating is stopped. When the color of the mixture turns to claret-red, the mixture was boiled for $15 \mathrm{~min}$, cooled to the room temperature, and stored at $4{ }^{\circ} \mathrm{C}$ for later use.

AuNRs was synthesized using seed-mediated method, and some improvements were made [36,37]. Total of $1.0 \mathrm{~mL}$ of CTAB $\left(0.2 \mathrm{~mol} \mathrm{~L}^{-1}\right)$ and $1.0 \mathrm{~mL}$ of $\mathrm{HAuCl}_{4}\left(0.5 \mathrm{mmol} \mathrm{L}^{-1}\right)$ were mixed in a glassy bottle, and $0.12 \mathrm{~mL}$ of $\mathrm{NaBH}_{4}\left(0.01 \mathrm{~mol} \mathrm{~L}^{-1}\right)$ was further added into the above mixture, and stirred gently for $2 \mathrm{~min}$ (the color of the mixture changes from yellow to brownish yellow) as the seed liquid. After $40.0 \mathrm{~mL}$ of CTAB $\left(0.2 \mathrm{~mol} \mathrm{~L}^{-1}\right)$ and $40.0 \mathrm{~mL}$ of $\mathrm{HAuCl}_{4}\left(1 \mathrm{mmol} \mathrm{L}^{-1}\right)$ were evenly mixed, $0.8 \mathrm{~mL}$ of $\mathrm{AgNO}_{3}\left(0.01 \mathrm{~mol} \mathrm{~L}^{-1}\right), 0.64 \mathrm{~mL}$ of ascorbic acid $\left(0.1 \mathrm{~mol} \mathrm{~L}^{-1}\right)$, and $0.8 \mathrm{~mL}$ of $\mathrm{HCl}\left(2 \mathrm{~mol} \mathrm{~L}^{-1}\right)$ were added in order, and mixed well as the growth liquid. Take $0.28 \mathrm{~mL}$ of seed liquid into the above growth liquid, and finally put the mixture into a $30^{\circ} \mathrm{C}$ water bath for $12 \mathrm{~h}$ without stirring. The mixture was centrifuged at 10,000 rpm for $20 \mathrm{~min}$ to remove CTAB. The AuNRs product was reconstituted with $40.0 \mathrm{~mL}$ of ultrapure water for use.

\subsection{Preparation of Immune Signal Probe}

The obtained colloidal Au SP and NRs were employed to prepare the immune signal probes (AuSP-Ab and AuNRs-Ab). The anti-ZEN-Ab was modified onto the AuSP and AuNRs by electrostatic adsorption and the whole process is as follows (Figure 1A). First, a certain volume (0, 1.0, 2.0, 3.0, 4.0, and $5.0 \mu \mathrm{L})$ of $\mathrm{K}_{2} \mathrm{CO}_{3}\left(0.2 \mathrm{~mol} \mathrm{~L}^{-1}\right)$ was mixed with $0.8 \mathrm{~mL}$ of the colloidal AuSP or AuNRs to adjust the $\mathrm{pH}$, and then the anti-ZEN-Ab $\left(1.0 \mathrm{mg} \mathrm{mL}^{-1}\right)$ at a volume of 1.0, 2.0, 3.0, 4.0, and $5.0 \mu \mathrm{L}$ was also added and incubated at room temperature for $1 \mathrm{~h}$. Then, $8.0 \mu \mathrm{L}$ of PEG-20000 (10\%) and $16.0 \mu \mathrm{L}$ of BSA $(20 \%)$ were added and incubated for $0.5 \mathrm{~h}$. The obtained mixture was centrifuged at $8000 \mathrm{rpm}$ for $20 \mathrm{~min}$ at $4{ }^{\circ} \mathrm{C}$. The solid product was further reconstituted with $80 \mu \mathrm{L}$ of gold-label working buffer at $\mathrm{pH} 7.0$.

\subsection{Preparation and Test Procedure of Immunochromatographic Test Strips}

Immunochromatographic test strip was composed of four parts, from left to right (the sample pad, conjugate pad, NC membrane, and absorbent pad) (Figure 1B). These four parts were sequentially pasted on the PVC sheets. Goat anti-mouse $\mathrm{Ab}$ was fixed on the control line ( $\mathrm{C}$ line) at $0.6 \mu \mathrm{L} \mathrm{cm}^{-1}$, and the conjugate of ZEN-OVA was fixed on the test line (T line) at $0.6 \mu \mathrm{L} \mathrm{cm}^{-1}$ for $0.5 \mathrm{~cm}$ to $\mathrm{C}$ line. Put the sliced membrane into $37^{\circ} \mathrm{C}$ incubator and incubate it overnight, then cut into strips with a width of $0.38 \mathrm{~cm}$. For the AuSP and AuNRs-ICA test strips, $100 \mu \mathrm{L}$ of ZEN solution (standard or sample), $2.0 \mu \mathrm{L}$ of signal probe (AuSP-Ab or AuNRs-Ab) solution, and $12 \mu \mathrm{L}$ of gold-label working buffer were fully mixed in a tube and uploaded onto the sample pad. The results were observed after $10 \mathrm{~min}$. 
A

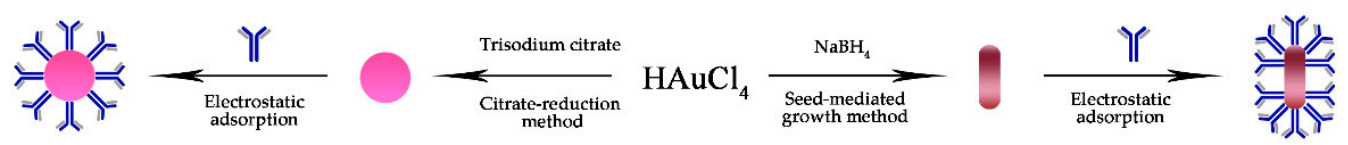

B
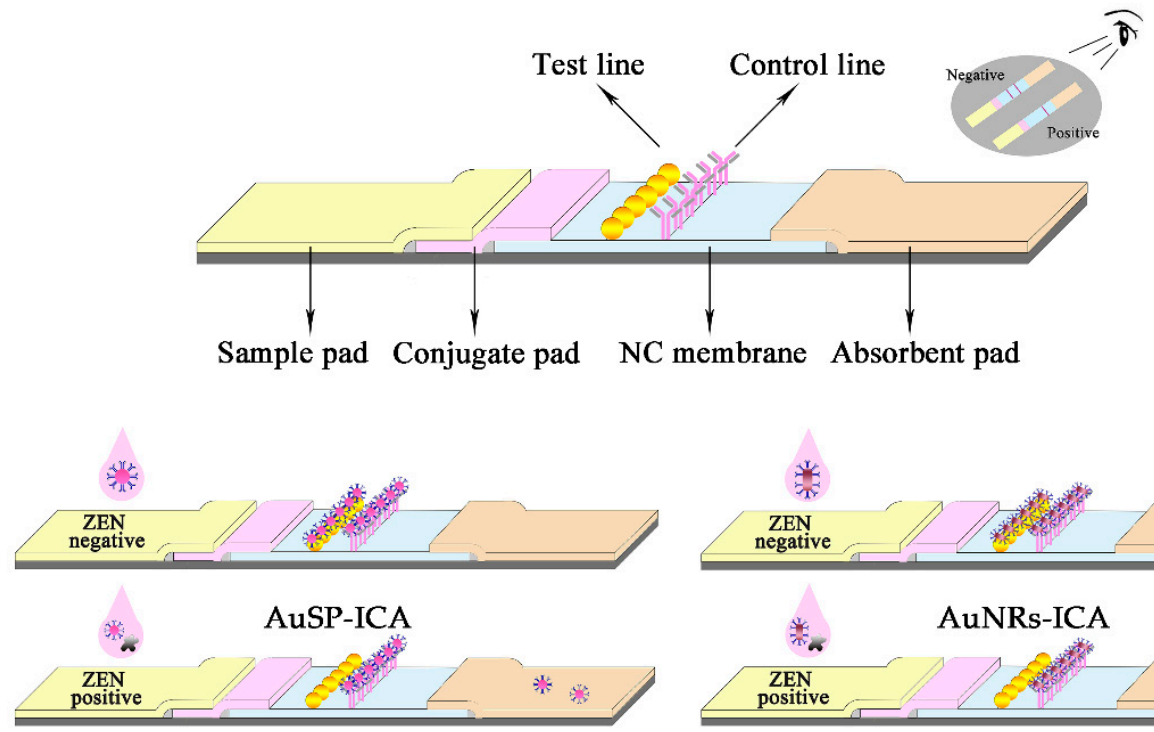

Colloidal AuSP AuNRs
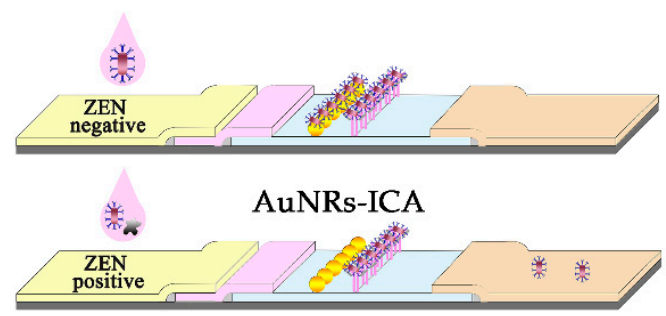

AuSP-Ab
ZEN-OVA $\|^{*}$ Goat anti-mouse Ab

ZEN If anti-ZEN-Ab

Figure 1. Schematic of AuSP-ICA and AuNRs-ICA. (A) The synthesis of AuSP and AuNRs and the coupling process with anti-ZEN-Ab; (B) structure of the immunochromatographic assay (ICA) strip and the test procedure for the ICAs.

\subsection{Sample Analysis}

Total of $5.0 \mathrm{~g}$ of cereal sample (corn and wheat powder) was accurately weighed, passed through a $0.05-2 \mathrm{~mm}$ sieve, and placed into a $50 \mathrm{~mL}$ glass centrifuge tube. A certain concentration of ZEN standard solution was added to control ZEN concentration in samples ranging from 0 to $80 \mu \mathrm{g} \mathrm{kg}^{-1}$. After standing for $5 \mathrm{~min}$, the mixture was shaken for $15 \mathrm{~min}$ by a vortex machine. A total of $10.0 \mathrm{~mL}$ of the solution containing methanol and PBS $(5 / 5, V / V)$ for sample extraction was added into the tube. The mixture was centrifuged at $8000 \mathrm{rpm}$ for $20 \mathrm{~min}$ and the supernatant was filtered using a $0.22 \mu \mathrm{m}$ filter, and the filtrate was diluted eight times using sample diluent for visual analysis using the AuSP and AuNRs test strips.

\section{Results and Discussions}

\subsection{Synthesis and Characterization of AuSP and AuNRs}

Colloidal AuSP was synthesized according to a classical method of trisodium citrate reduction. Figure 2A shows the images of digital and transmission electron microscope (TEM) of the prepared colloidal AuSP. It was clearly observed that the size of colloidal AuSP was uniform with an average particle size of $20.95 \mathrm{~nm}$. From the digital image, the solution of colloidal AuSP was claret-red without obvious precipitation. The absorption curve of UV spectra was smooth, and the maximum absorption peak at $522 \mathrm{~nm}$ was narrow and high, which indicated the uniform particle size of the prepared colloidal AuSP. 
A

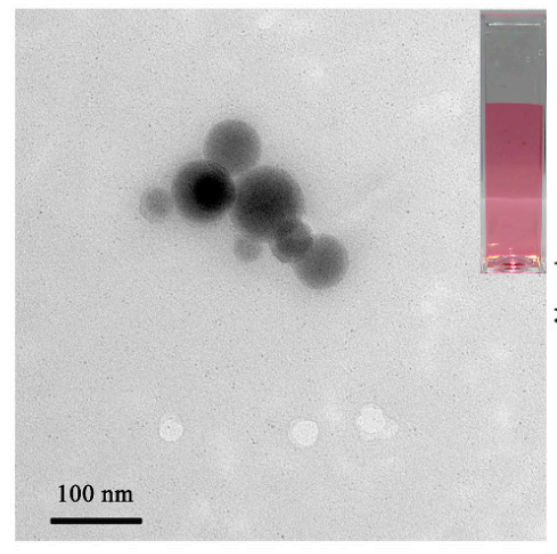

B

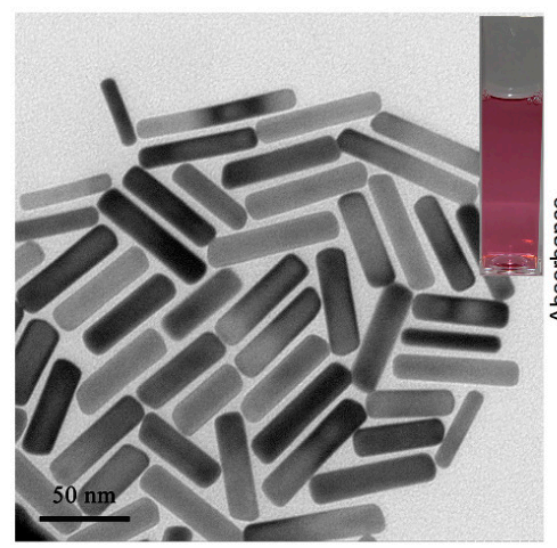



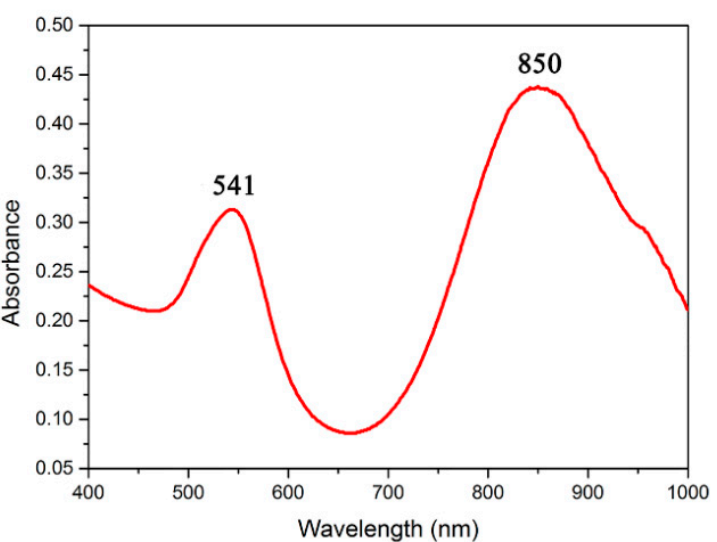

Figure 2. Transmission electron microscope (TEM) image and UV spectra of the prepared Au nanomaterials (A) colloidal AuSP (B) AuNRs.

The AuNRs was prepared according to the classical seed-mediated method. The difference is that by controlling the amount of $\mathrm{HCl}\left(0.8 \mathrm{~mL}, 2 \mathrm{~mol} \mathrm{~L}^{-1}\right)$, the irregular shape of AuNRs is reduced. Figure 2B shows that the size of the prepared AuNRs was uniform and the aspect ratio was about 3.98. The AuNRs solution is shown in claret-colored. The UV-visible spectra of AuNRs indicated that the centers of the transverse and longitudinal SPR peaks are located at $541 \mathrm{~nm}$ and $850 \mathrm{~nm}$, respectively.

\subsection{Optimization of the Parameters of ICAs}

The experimental parameters including the $\mathrm{pH}$ for probe coupling, the anti-ZEN-Ab coupling ratio, the pore size of the membrane, the amount of goat anti-mouse $\mathrm{Ab}$ on the $\mathrm{C}$ line, the amount of coated antigen (ZEN-OVA) on the $\mathrm{T}$ line, and the buffer solution were optimized in detail to construct an effective immunochromatographic method for ZEN analysis.

The optimal experimental conditions are determined by the three following factors: (a) No gathering during the coupling process; (b) having color on the test strip during the detection process; (c) when the negative sample is detected, the color of the $\mathrm{C}$ and $\mathrm{T}$ lines are consistent. The following experimental conditions were found to obtain the best results: (1) Optimal probe coupling $\mathrm{pH}$ : $3.0 \mu \mathrm{L}$ of $\mathrm{K}_{2} \mathrm{CO}_{3}\left(0.2 \mathrm{~mol} \mathrm{~L}^{-1}\right)$ for AuSP-ICA, $4.0 \mu \mathrm{L}$ of $\mathrm{K}_{2} \mathrm{CO}_{3}\left(0.2 \mathrm{~mol} \mathrm{~L}^{-1}\right)$ for AuNRs-ICA; (2) the best anti-ZEN-Ab coupling ratio: $5.0 \mu \mathrm{L}$ anti-ZEN-Ab for AuSP-ICA (the mass ratio of $\mathrm{HAuCl}_{4} / \mathrm{Ab}$ was 16/1), $5.0 \mu \mathrm{L}$ anti-ZEN-Ab for AuNRs-ICA (the mass ratio of $\mathrm{HAuCl}_{4} / \mathrm{Ab}$ was 32/1); (3) the optimal pore size of the membrane: HF135s NC membrane for AuSP-ICA and AuNRs-ICA; (4) the amount of goat anti-mouse $\mathrm{Ab}$ on $\mathrm{C}$ line: $0.16 \mu \mathrm{g} \mathrm{cm}^{-1}$ for AuSP-ICA and AuNRs-ICA; (5) optimal amount of ZEN-OVA on T line: $0.16 \mu \mathrm{g} \mathrm{cm}^{-1}$ for AuSP-ICA and AuNRs-ICA; (6) optimum determination buffer: for AuSP-ICA and AuNRs-ICA, pH 7.4 phosphate buffer saline (PBS) buffer $\left(0.01 \mathrm{~mol} \mathrm{~L}^{-1}\right)$. 


\subsection{The Sensitivity and Specificity of the AuSP-ICA and AuNRs-ICA}

Both the developed ICAs in this work are based on the principle of competitive reaction between antigen and $\mathrm{Ab}$. The detection process is described as follows: The ZEN sample testing solution and the immune signal probes (AuSP-Ab and AuNRs- $\mathrm{Ab}$ ) were mixed evenly and uploaded onto the sample pad. The mixture is chromatographed gradually toward the absorbent pad because of the capillary forces. For negative samples, the red signal probes were intercepted by ZEN-OVA fixed on the T line which appeared red, and the excess probes continued to be chromatographed upwards and captured by the goat anti-mouse $\mathrm{Ab}$ fixed on the $\mathrm{C}$ line which was also red. For positive samples, $\mathrm{ZEN}$ in the sample solution and ZEN-OVA on the T line competitively bound to the signal probe, causing the $\mathrm{T}$ line to become lighter in color. As the ZEN content in the sample solution increased, the color of the T line gradually disappeared, and only the $C$ line was observed to be red. The ZEN concentration that caused the red or purple disappearance of the $\mathrm{T}$ line were defined as the limits of detection (LOD) of these two assays. If the $\mathrm{C}$ line disappeared, the $\mathrm{T}$ line was in color, or both the $\mathrm{C}$ and $\mathrm{T}$ lines disappeared during testing, it indicated that the test strips were invalid. Under the optimized conditions above, two ICAs have been developed as different sensitivity and semi-quantitative detection (Figure 3).

\section{A}

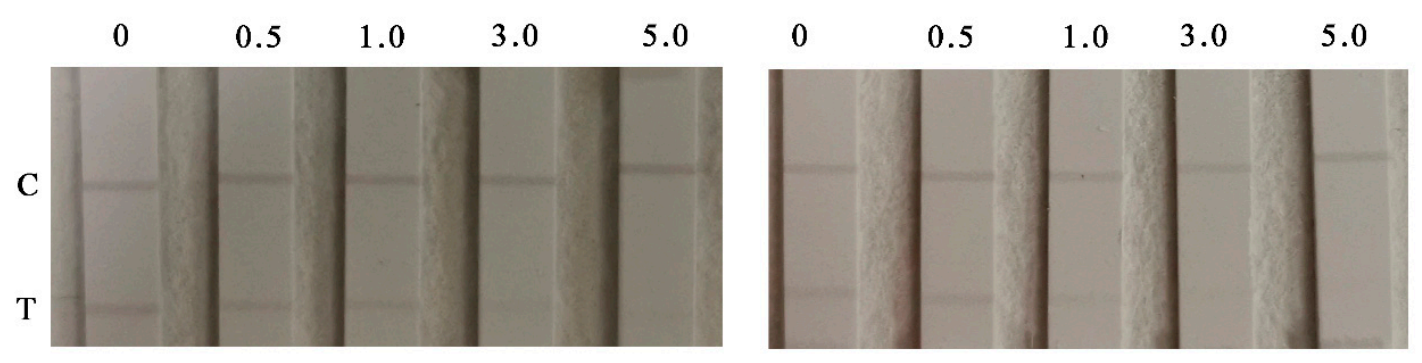

Figure 3. Results of zearalenone (ZEN) detection using AuSP-ICA and AuNRs-ICA strips. (A) colloidal AuSP (B) AuNRs; tested ZEN concentrations in PBS buffer (pH 7.4): 0, 0.5, 1.0, 3.0, and $5.0 \mu \mathrm{g} \mathrm{L}^{-1}$.

For AuSP-ICA, the red color of the T line gradually became lighter as the ZEN concentration increases, and eventually disappeared when the ZEN concentration was $5.0 \mu \mathrm{g} \mathrm{L} \mathrm{L}^{-1}$ (Figure 3A). For AuNRs-ICA, the red color of the T line was also shallower as the ZEN concentration increases gradually and eventually disappeared when the ZEN concentration was $3.0 \mu \mathrm{g} \mathrm{L}^{-1}$ (Figure 3B). Therefore, the LODs of the AuSP-ICA and AuNRs-ICA in visual analysis were $5.0 \mu \mathrm{g} \mathrm{L}^{-1}$ and $3.0 \mu \mathrm{g} \mathrm{L}{ }^{-1}$, respectively. Based on the same amount of anti-ZEN-Ab and ZEN-OVA in the test, the developed AuNRs-ICA was more sensitive than the AuSP-ICA. This may be due to the unique structure of AuNRs and their different adsorption ability to antibodies, which also means that AuNRs have broad application prospects in rapid visual detection.

Ten mycotoxins including five structural analogs of ZEN ( $\alpha$-zearalenol, $\beta$-zearalenol, $\alpha$-zearalanol, $\beta$-zearalanol, zearalanone), $\mathrm{AFB}_{1}, \mathrm{OTA}, \mathrm{T}-2$ toxin, $\mathrm{FB}_{1}$, and $\mathrm{DON}$ were selected to evaluate the specificity of the two developed ICAs in the work. The chemical structure for ten mycotoxins is shown in Table S1. From the results, when the concentration of zearalanone was $300 \mu \mathrm{g} \mathrm{L}^{-1}$, the $\mathrm{T}$ line on the AuSP-ICA and AuNRs-ICA test strip disappeared. But for four other structural analogs of ZEN, the concentration should achieve $50 \mu \mathrm{g} \mathrm{L}^{-1}$ to cause the $\mathrm{T}$ line to disappear. The concentrations of $\mathrm{AFB}_{1}$, OTA, T-2 toxin, $\mathrm{FB}_{1}$, and DON were $1000 \mu \mathrm{g} \mathrm{L}^{-1}$, the color of $\mathrm{T}$ line can still be observed. These results indicated that the proposed AuSP-ICA and AuNRs-ICA have minor cross-reactions occurring between ZEN and five other structural analogs, and no cross-reactivity with $\mathrm{AFB}_{1}, \mathrm{OTA}, \mathrm{T}-2$ toxin, $\mathrm{FB}_{1}, \mathrm{DON}$.

\subsection{Detection of ZEN in Practical Samples}

The matrix components and organic reagents in the sample extract would affect the specific binding of ZEN-OVA and anti-ZEN-Ab in the detection process. A series of ZEN solutions were 
constructed using different sample diluent and tested by the AuSP-ICA and AuNRs-ICA to eliminate the potential matrix effects. By comparison of the test results obtained using sample extract at different diluted times, it was demonstrated that the eight times diluted sample extract can obtain the elimination line compared with that in PBS buffer. That means the matrix component and organic reagent in the extract did not interfere with the specific binding of ZEN-OVA and anti-ZEN-Ab. As a result, the eight times diluted sample extract using the PBS buffer of $\mathrm{pH} 7.4$ was chosen for further research.

Cereal samples (including corn and wheat powder) were purchased from a local supermarket. Figure 4 shows the detection results of AuSP-ICA and AuNRs-ICA strips for visual detection of ZEN in spiked food samples at various concentrations of $0,20,40,60$, and $80 \mu \mathrm{g} \mathrm{kg}-1$. It is obviously shown that for AuSP-ICA, when the ZEN concentration in cereal samples was $60 \mu \mathrm{g} \mathrm{kg}{ }^{-1}$ (LOD), the $\mathrm{T}$ line disappeared (Figure 4A). The AuNRs-ICA strip can obtain the elimination line at the ZEN sample concentration of $40 \mu \mathrm{g} \mathrm{kg}^{-1}$ (LOD), indicating the AuNRs-ICA strip has better sensitivity and wider detection range than the AuSP-ICA (Figure 4A'). Figure $4 \mathrm{~B}$ and $\mathrm{B}^{\prime}$ shows the test results using AuSP-ICA and AuNRs-ICA to detect ZEN in wheat samples, which have the same visual LODs with corn. These results demonstrated that the developed AuSP-ICA and AuNRs-ICA strips have good response to the analyte $\mathrm{ZEN}$ and can be applied in the detection of ZEN in practical samples. These results also demonstrated that it is feasible to employ AuNRs material as signal probe marker for the detection of small molecule contaminants in the ICAs. Table 1 shows a comparison of the results from different reported methods, signifying the merits of the developed AuSP-ICA and AuNRs-ICA in rapid screening and detection of ZEN in large number of samples.

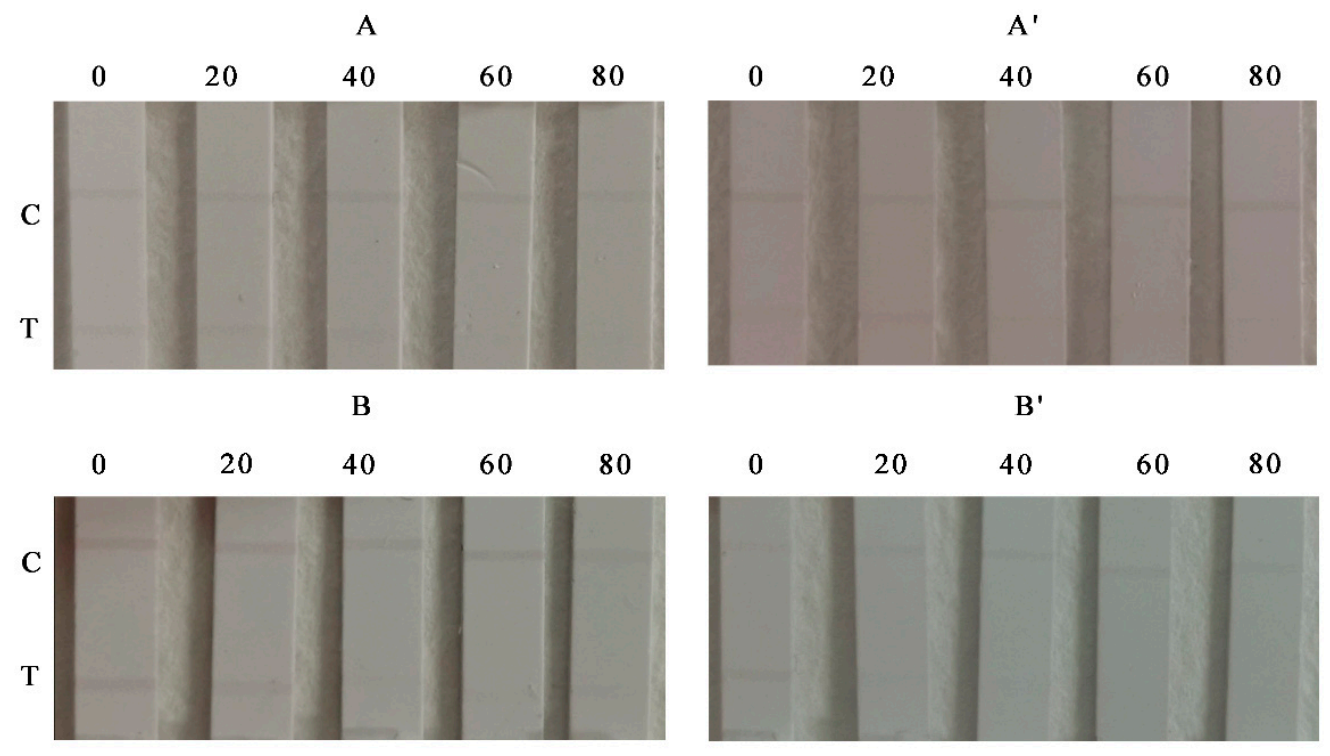

Figure 4. Results of ZEN detection in spiked cereal samples using AuSP-ICA (A: corn; B: wheat) and AuNRs-ICA (A': corn; B': wheat) strips. Spiked ZEN concentrations in cereal samples: 0, 20, 40, 60, and $80 \mu \mathrm{g} \mathrm{kg}^{-1}$. 
Table 1. Results of the comparison of different reported methods for ZEN detection.

\begin{tabular}{|c|c|c|c|c|}
\hline Methods & 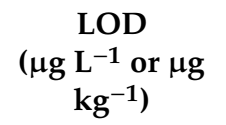 & Test Time & Samples & References \\
\hline Ultra HPLC-MS/MS & 0.05 & $7 \mathrm{~min}$ & Chinese yam, coix seed & [11] \\
\hline GC-MS & 0.01 & $1 \mathrm{~h}$ & Vegetable oil & [13] \\
\hline $\begin{array}{l}\text { Electrochemical } \\
\text { immunosensor }\end{array}$ & $1.5 \times 10^{-4} / 0.25$ & More than $1 \mathrm{~h}$ & Maize/Beer, wine & [38]/[39] \\
\hline ELISA & $\begin{array}{c}0.04 / 0.15 / 4 \times \\
10^{-3}\end{array}$ & $15-30 \mathrm{~min}$ & $\begin{array}{l}\text { Corn/Chicken, pork, } \\
\text { beef/Wine }\end{array}$ & {$[14,15,40]$} \\
\hline Colloidal Au-based ICA & $10 / 6$ & $15 \mathrm{~min}$ & $\begin{array}{l}\text { Maize, wheat, } \\
\text { rice/Corn, wheat, } \\
\text { feedstuffs }\end{array}$ & {$[17,21]$} \\
\hline Fluorescent -ICAs & $0.1 / 1$ & $20 \mathrm{~min} / 8 \mathrm{~min}$ & $\begin{array}{c}\text { Maize, wheat, } \\
\text { vegetable oil/Maize }\end{array}$ & {$[19] /[20]$} \\
\hline $\begin{array}{l}\text { Aptamer-based lateral } \\
\text { flow test strip }\end{array}$ & 20 & $5 \mathrm{~min}$ & Corn & [41] \\
\hline $\begin{array}{l}\text { AuSP-ICA and } \\
\text { AuNRs-ICA }\end{array}$ & 5.0 and 3.0 & $10 \mathrm{~min}$ & Corn; wheat & This work \\
\hline
\end{tabular}

\section{Conclusions}

This study has developed two kinds of visual immunoassay test strips based on the colloidal AuSP and AuNRs with good specificity and high sensitivity for ZEN toxins in cereals. This is the first time that the AuNRs are used as signal probe in immune test strip for rapid detection of ZEN, which has proved the feasibility and merits of AuNRs as a signal probe for visual detection. It also provided the application reference for the research in the field of rapid food safety. Although the established two ICA test strips can only provide qualitative or semi-quantitative analysis results, the entire detection process can be completed in $10 \mathrm{~min}$, and the sensitivity provided can meet the required maximum residue limit. This provides an effective technical support for the rapid screening and detection of ZEN toxin in cereals.

Supplementary Materials: The following are available online at http://www.mdpi.com/2304-8158/9/3/281/s1. Table S1: The chemical structure of the tested mycotoxins in the research.

Author Contributions: M.P. provided the idea and financial support of the research; T.M. carried out the whole experiment (M.P. and T.M. contributed to this article equally); J.Y. verified some of the experimental results; S.L. (Shijie Li) analyzed and compared the results of the experiment; S.L. (Shengmiao Liu) verified some of the experimental results; S.W. provided the framework of the paper and finally checked the quality of the article. All authors have read and agreed to the published version of the manuscript.

Funding: This research was funded by the National Natural Science Foundation of China (No. 31972147), Tianjin Technical Expert Project (No. 19JCTPJC52700), Project of Tianjin Science and Technology Plan (No. 18ZYPTJC00020), and the Open Project Program of State Key Laboratory of Food Nutrition and Safety, Tianjin University of Science and Technology (SKLFNS-KF-201907). The APC was funded by Project of Tianjin Science and Technology Plan (No. 18ZYPTJC00020).

Conflicts of Interest: The authors declare no conflict of interest.

\section{References}

1. Golge, O.; Kabak, B. Occurrence of deoxynivalenol and zearalenone in cereals and cereal products from Turkey. Food Control 2020, 110, 106982. [CrossRef]

2. Llorent-Martinez, E.J;; Fernandez-Poyatos, M.P.; Ruiz-Medina, A. Automated fluorimetric sensor for the determination of zearalenone mycotoxin in maize and cereals feedstuff. Talanta 2019, 191, 89-93. [CrossRef] [PubMed] 
3. Reddy, K.E.; Song, J.; Lee, H.J.; Kim, M.; Kim, D.W.; Jung, H.J.; Kim, B.; Lee, Y.; Yu, D.; Kim, D.W.; et al. Effects of High Levels of Deoxynivalenol and zearalenone on growth performance, and hematological and immunological parameters in pigs. Toxins 2018, 10, 114. [CrossRef] [PubMed]

4. Gao, X.; Sun, L.H.; Zhang, N.Y.; Li, C.; Zhang, J.C.; Xiao, Z.H.; Qi, D.S. Gestational zearalenone exposure causes reproductive and developmental toxicity in pregnant rats and female offspring. Toxins 2017, 9, 21. [CrossRef] [PubMed]

5. Yang, D.C.; Jiang, X.W.; Sun, J.X.; Li, X.; Li, X.S.; Jiao, R.; Peng, Z.Y.; Li, Y.Q.; Bai, W.B. Toxic effects of zearalenone on gametogenesis and embryonic development: A molecular point of review. Food Chem. Toxicol. 2018, 119, 24-30. [CrossRef]

6. Rogowska, A.; Pomastowski, P.; Sagandykova, G.; Buszewski, B. Zearalenone and its metabolites: Effect on human health, metabolism and neutralisation methods. Toxicon 2019, 162, 46-56. [CrossRef]

7. Yang, Z.D.; Xue, K.S.; Sun, X.L.; Williams, P.L.; Wang, J.S.; Tang, L.L. Toxicogenomic responses to zearalenone in Caenorhabditis elegans reveal possible molecular mechanisms of reproductive toxicity. Food Chem. Toxicol. 2018, 122, 49-58. [CrossRef]

8. Lecomte, S.; Demay, F.; Pham, T.H.; Moulis, M.; Efstathiou, T.; Chalmel, F.; Pakdel, F. Deciphering the molecular mechanisms sustaining the estrogenic activity of the two major dietary compounds zearalenone and apigenin in ER-positive breast cancer cell lines. Nutrients 2019, 11, 237. [CrossRef]

9. Kos, J.; Hajnal, E.J.; Malachová, A.; Steiner, D.; Stranska, M.; Krska, R.; Poschmaier, B.; Sulyok, M. Mycotoxins in maize harvested in Republic of Serbia in the period 2012-2015. Part 1: Regulated mycotoxins and its derivatives. Food Chem. 2020, 312, 126034. [CrossRef]

10. Zhang, F.Y.; Liu, B.; Liu, G.Z.; Sheng, W.; Zhang, Y.; Liu, Q.; Wang, S. Novel magnetic nanobeads-based fluoroimmunoassays for zearalenone detection in cereals using protein $\mathrm{G}$ as the recognition linker. Sens. Actuat. B Chem. 2018, 270, 149-157. [CrossRef]

11. Sun, S.J.; Yao, K.; Zhao, S.J.; Zheng, P.M.; Wang, S.H.; Zeng, Y.Y.; Liang, D.M.; Ke, Y.B.; Jiang, H.Y. Determination of aflatoxin and zearalenone analogs in edible and medicinal herbs using a group-specific immunoaffinity column coupled to ultra-high-performance liquid chromatography with tandem mass spectrometry. J. Chromatogr. B 2018, 1092, 228-236. [CrossRef] [PubMed]

12. Han, Z.; Jiang, K.Q.; Fan, Z.C.; Mavungu, J.D.D.; Dong, M.F.; Guo, W.B.; Fan, K.; Campbell, K.; Zhao, Z.H.; $\mathrm{Wu}$, Y.J. Multi-walled carbon nanotubes-based magnetic solid-phase extraction for the determination of zearalenone and its derivatives in maize by ultra-high performance liquid chromatography-tandem mass spectrometry. Food Control 2017, 79, 177-184. [CrossRef]

13. Qian, M.R.; Zhang, H.; Wu, L.Q.; Jin, N.; Wang, J.M.; Jiang, K.Z. Simultaneous determination of zearalenone and its derivatives in edible vegetable oil by gel permeation chromatography and gas chromatography-triple quadrupole mass spectrometry. Food Chem. 2015, 166, 23-28. [CrossRef] [PubMed]

14. Zhang, X.; Wang, X.; Sun, M.J.; Zhang, X.F.; Song, H.H.; Yan, Y.X.; Sun, J.H.; Li, X.L.; Fang, W.H. A magnetic nanoparticle based enzyme-linked immunosorbent assay for sensitive quantification of zearalenone in cereal and feed samples. Toxins 2015, 7, 4216-4231. [CrossRef] [PubMed]

15. Li, R.; Jia, L.Z.; Yang, J.Y.; Xu, Z.L.; Wang, H.; Lei, H.T.; Sun, Y.M.; Shen, Y.D. An indirect competitive enzyme-linked immunosorbent assay for simultaneous determination of florfenicol and thiamphenicol in animal meat and urine. Chin. J. Anal. Chem. 2018, 46, 1321-1328. [CrossRef]

16. Jiang, X.M.; Li, X.M.; Yang, Z.; Eremin, S.A.; Zhang, X.Y. Evaluation and optimization of three different immunoassays for rapid detection zearalenone in fodders. Food Anal. Method 2017, 10, 256-262. [CrossRef]

17. Li, S.J.; Sheng, W.; Wen, W.J.; Gu, Y.; Wang, J.P.; Wang, S. Three kinds of lateral flow immunochromatographic assays based on the use of nanoparticle labels for fluorometric determination of zearalenone. Microchim. Acta 2018, 185, 238. [CrossRef]

18. Hou, S.L.; Ma, J.J.; Cheng, Y.Q.; Wang, H.G.; Sun, J.H.; Yan, Y.X. One-stop rapid detection of fumonisin $B_{1}$, dexyonivalenol and zearalenone in grains. Food Control 2020, 107107. [CrossRef]

19. Li, S.J.; Wang, J.P.; Sheng, W.; Wen, W.J.; Gu, Y.; Wang, S. Fluorometric lateral flow immunochromatographic zearalenone assay by exploiting a quencher system composed of carbon dots and silver nanoparticles. Microchim. Acta 2018, 185, 388. [CrossRef]

20. Zhang, F.Y.; Liu, B.; Sheng, W.; Zhang, Y.; Liu, Q.; Li, S.J.; Wang, S. Fluoroimmunoassays for the detection of zearalenone in maize using cdte/cds/zns quantum dots. Food Chem. 2018, 255, 421-428. [CrossRef] 
21. Wang, Y.K.; Shi, Y.B.; Zou, Q.; Sun, J.H.; Chen, Z.F.; Wang, H.A.; Li, S.Q.; Yan, Y.X. Development of a rapid and simultaneous immunochromatographic assay for the determination of zearalenone and fumonisin $B_{1}$ in corn, wheat and feedstuff samples. Food Control 2013, 31, 180-188. [CrossRef]

22. Li, X.; Li, P.W.; Zhang, Q.; Li, R.; Zhang, W.; Zhang, Z.W.; Ding, X.X.; Tang, X.Q. Multi-component immunochromatographic assay for simultaneous detection of aflatoxin $\mathrm{B}_{1}$, ochratoxin $\mathrm{A}$ and zearalenone in agro-food. Biosens. Bioelectron. 2013, 49, 426-432. [CrossRef] [PubMed]

23. Man, Y.; Liang, G.; Jia, F.C.; Li, A.; Fu, H.L.; Wang, M.; Pan, L.G. Development of an immunochromatographic strip test for the rapid detection of alternariol monomethyl ether in fruit. Toxins 2017, 9, 152. [CrossRef] [PubMed]

24. Liu, B.; Wang, L.L.; Tong, B.; Zhang, Y.; Sheng, W.; Pan, M.F.; Wang, S. Development and comparison of immunochromatographic strips with three nanomaterial labels: Colloidal gold, nanogold-polyaniline-nanogold microspheres (GPGs) and colloidal carbon for visual detection of salbutamol. Biosens. Bioelectron. 2016, 85, 337-342. [CrossRef]

25. Hu, W.G.; Yan, Z.Y.; Li, H.M.; Qiu, J.H.; Zhang, D.D.; Li, P.; Pan, T.; Guo, H.J. Development of a new colloidal gold immunochromatographic strip for rapid detecting subgroup A of avian leukosis virus using colloidal gold nanoparticles. Biochem. Eng. J. 2019, 148, 16-23. [CrossRef]

26. Niazi, S.; Wang, X.L.; Pasha, I.; Khan, I.M.; Zhao, S.; Shoaib, M.; Wu, S.J.; Wang, Z.P. A novel bioassay based on aptamer-functionalized magnetic nanoparticle for the detection of zearalenone using time resolved-fluorescence $\mathrm{NaYF}_{4}$ : Ce/Tb nanoparticles as signal probe. Talanta 2018, 186, 97-103. [CrossRef]

27. Duan, H.; Li, Y.; Shao, Y.N.; Huang, X.L.; Xiong, Y.H. Multicolor quantum dot nanobeads for simultaneous multiplex immunochromatographic detection of mycotoxins in maize. Sens. Actuat. B Chem. 2019, 291, 411-417. [CrossRef]

28. Czeh, A.; Mandy, F.; Feher-Toth, S.; Torok, L.; Mike, Z.; Koszegi, B.; Lustyik, G. A flow cytometry based competitive fluorescent microsphere immunoassay (CFIA) system for detecting up to six mycotoxins. J. Immunol. Methods 2012, 384, 71-80. [CrossRef]

29. Shen, H.C.; Xu, F.; Xiao, M.; Fu, Q.Q.; Cheng, Z.Z.; Zhang, S.W.; Huang, C.H.; Tang, Y. New lateral-flow immunochromatographic strip combined with quantum dot nanobeads and gold nanoflowers for rapid detection of tetrodotoxin. Analyst 2017, 142, 4393-4398. [CrossRef]

30. Xiong, Y.; Pei, K.; Wu, Y.Q.; Duan, H.; Lai, W.H.; Xiong, Y.H. Plasmonic ELISA based on enzyme-assisted etching of Au nanorods for the highly sensitive detection of aflatoxin $\mathrm{B}_{1}$ in corn samples. Sens. Actuat. B Chem. 2018, 267, 320-327. [CrossRef]

31. Xu, X.; Liu, X.J.; Li, Y.B.; Ying, Y.B. A simple and rapid optical biosensor for detection of aflatoxin $B_{1}$ based on competitive dispersion of gold nanorods. Biosens. Bioelectron. 2013, 47, 361-367. [CrossRef] [PubMed]

32. Park, J.H.; Byun, J.Y.; Mun, H.; Shim, W.B.; Shin, Y.B.; Li, T.; Kim, M.G. A regeneratable, label-free, localized surface plasmon resonance (LSPR) aptasensor for the detection of ochratoxin A. Biosens. Bioelectron. 2014, 59, 321-327. [CrossRef] [PubMed]

33. Yao, S.G.; Cai, H.H.; Liu, M.; Yang, P.H. Fluorescent labeling of cellular targets and multicolor imaging with gold nanorods. Dye. Pigment. 2014, 101, 286-294. [CrossRef]

34. Pourjavadi, A.; Bagherifard, M.; Doroudian, M. Synthesis of micelles based on chitosan functionalized with gold nanorods as a light sensitive drug delivery vehicle. Int. J. Biol. Macromol. 2020, 149, 809-818. [CrossRef]

35. Yuan, D.; Liu, J.J.; Yan, H.H.; Li, C.M.; Huang, C.Z.; Wang, J. Label-free gold nanorods sensor array for colorimetric detection and discrimination of biothiols in human urine samples. Talanta 2019, 203, 220-226. [CrossRef]

36. Nikoobakht, B.; El-Sayed, M.A. Preparation and growth mechanism of gold nanorods (NRs) using seed-mediated growth method. Chem. Mater. 2003, 15, 1957-1962. [CrossRef]

37. Deng, D.D.; Yang, H.; Liu, C.; Zhao, K.; Li, J.G.; Deng, A.P. Ultrasensitive detection of Sudan I in food samples by a quantitative immunochromatographic assay. Food Chem. 2019, 277, 595-603. [CrossRef]

38. Riberi, W.I.; Tarditto, L.V.; Zon, M.A.; Arévalo, F.J.; Fernández, H. Development of an electrochemical immunosensor to determine zearalenone in maize using carbon screen printed electrodes modified with multi-walled carbon nanotubes/polyethyleneimine dispersions. Sens. Actuat. B Chem. 2018, 254, 1271-1277. [CrossRef] 
39. Goud, K.Y.; Kumar, V.S.; Hayat, A.; Gobi, K.V.; Song, H.; Kim, K.H.; Marty, J.L. A highly sensitive electrochemical immunosensor for zearalenone using screen-printed disposable electrodes. Electroanal. Chem. 2019, 832, 336-342. [CrossRef]

40. Hendrickson, O.D.; Chertovich, J.O.; Zherdev, A.V.; Sveshnikov, P.G.; Dzantiev, B.B. Ultrasensitive magnetic ELISA of zearalenone with pre-concentration and chemiluminescent detection. Food Control 2018, 84, 330-338. [CrossRef]

41. Wu, S.J.; Liu, L.H.; Duan, N.; Li, Q.; Zhou, Y.; Wang, Z.P. An aptamer-based lateral flow test strip for rapid detection of zearalenone in corn samples. J. Agric. Food Chem. 2018, 66, 1949-1954. [CrossRef] [PubMed]

(C) 2020 by the authors. Licensee MDPI, Basel, Switzerland. This article is an open access article distributed under the terms and conditions of the Creative Commons Attribution (CC BY) license (http://creativecommons.org/licenses/by/4.0/). 